\title{
The Learning by Playing Model for Busi- ness Education: How Students Learn Business Management in Simulation Game
}

\author{
Song Han ${ }^{1}$ Jian Cai ${ }^{2}$ Xiangdong Liu $^{3}$ Qiwen Wang ${ }^{1}$ \\ ${ }^{1}$ Guanghua School of Management, Peking University, 100871, P. R. China \\ ${ }^{2}$ PIER Institute, College of Engineering, Peking University, 100871, P. R. China \\ ${ }^{3}$ China Center for International Economic Exchanges, 100017, P. R. China
}

\begin{abstract}
Now more business schools use simulation technology to develop their students' capabilities. However, there are few frameworks and methodologies to understand the mechanism of student learning process in business simulation games. The BizSim game developed by Peking University is an innovative platform, which allows students to participate into the simulated business competition environment. The national online business competition based on BizSim provides students not only fun but skill improvement environment. Based on the game and competition, a qualitative study was conducted with data collection and a series of depth interviews (or focus group) with experts, scholars, and students across the country. The research constructs theoretical relationships and develops a grounded theory of business skills learning and development in a competing environment. The study finds that students who play the simulated business competition game use a participated learning model and become more professional, powerful and creative in their future professions. The learning by playing model provides an innovative approach to solving the
\end{abstract}

educational and technical challenges of business education.

Keywords: BizSim game, students, learning by palying, business education

\section{Introduction}

The reform of education systems in China is facing the challenges of improving the teaching quality and learning experience. The competition in graduate school entrance examination and job finding has been fierce. In the year of 2010, the number of students who will graduate from the colleges and universities will be more than 6,300,000 and increase $12.7 \%$ in 2008 [7]. Especially the traditional business education in China is losing attractions partly because more students are tired with outmoded teaching patterns and their parents are more concerned with increasing expensive fees than educational quality. Today, more and more students think that studying hard is not the best avenue to relax their pressure for helping them find competent jobs. Although it is common for university courses to teach isolated skills in the application of business technologies, many business schools do little in providing a context that help to reinforce students' hand-on skill and deep insight. 
Some leading business schools have realized that they can make use of the new learning mechanisms to enhance student self-efficacy, business insight and satisfaction. Students will learn more from practice and prepare for tomorrow's service for the society in an innovative way. On the other hand, business schools face the challenges to adjust their rigid institution and change the outmoded courses to meet students' real needs (especially attitudes, experiences and skills acquirement). To reach these goals, the research team at Peking University takes a new education change initiative and builds a platform called BizSim game for students to compete with each other in a virtual business environment without the boundary of schools. The objective is to provide students not only the knowledge they need today but also the capability to fast integrate them into the society and gain a competitive success in the future. How to overcome the gaps between teaching and learning using innovative "learning by playing" models? What mechanism is required to make this model more efficient and effective ?

These are the research problems we need to investigate and address.

This paper has the following structure: section two illustrates the changes of business schools and observes some gaps between teaching and learning. Section three provides an interpretation of a simulation game-BizSim and the "learning by playing" model of business education through a grounded theory research and propose a theory of aligning business skills with learning cycle. In section four, we discuss the implications and applications of the model as a complementary approach of routine class model. In the end, the paper draws a conclusion and provides further directions of this action research.

\section{Literature Review}

\subsection{Changing in current business education}

Nowadays, Business schools are expected to provide more practical courses for their students. Due to lack of enough more external companies resources, many business schools in the world have developed lots of simulation courses as complements of practice training. Students in business schools prefer learning by doing (or playing) learning by teaching. Some studies has provided some evidence that learning by doing also named experiential learning is more effective for students to better understand the business practice [3][12]. In these disciplines, there are much clinical training or learning by doingexperiential learning where "concrete experience is the basis for observation and reflection" [11]. For business education, Kolb [1976] also indicated that "The practice of management is best taught as a craft, rich in lessons derived from experience and oriented toward taking and responding to action". The demands for better managers and better leaders, and the demands for business knowledge are relentless, and these demands have already generated numerous alternative sources of supply [13].

\subsection{The gaps between teaching and learning in today's business edu- cation}

With rapid economic growth and open policies in China, more foreign enterprises have their subsection in China and many returnees work in the big cities as Beijing and Shanghai. Thus there are more both opportunities and challenges for graduated college students. Qualified role in future profession is expected to be supported by high-level skills and capacities. Meanwhile, the employees have been required more business insight, 
global visions and leadership. However, many enterprises are still pointing out that the human resources that they need could be hardly acquired in the current education systems at business schools.

\section{Four gaps in educational environment}

In previous studies of business simulations, game performance is generally considered the dependent variable of interest [1][9]. A critical task of business education is helping students develop knowledge structures of specific domains [16]. But based on the interview with the enterprise leaders, we identified that there are still some gaps between business educations and real requirements of both students and employers.

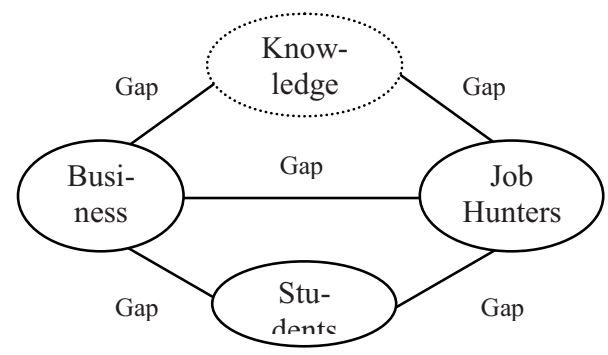

Fig. 1: The gaps of current business education.

These gaps in a business education market have result into many crises (i.e. MBA programs' failure and information system disciplinary crisis) which recently incurred more and more arguments in business education fields. Figure 1 illustrates the gaps among business schools, students and job hunters or employers:

Gap1: the gap between academic theories and practice in business schools. Many students do well in understanding theories, but don't know how to put them into practices. Thus the challenge of business schools is to design their curriculums in an innovative way to reduce the gap between theories and practices.

Gap2: the gap between offerings of business schools and requirements of ex- ternal companies. There is a disconnection between what business schools offer and what employers seek [8]. Since most of curriculums in business schools are taught separately and especially lack of practice or internship courses, the students are lack of opportunities of real practice. On the other hand, the cost and risk of using real project from companies as training course are very high. So there are more simulative courses and case studies introduced into the business curriculum instead of internship courses.

Gap3: the gap between students' interests and teaching models. For many students especially those lacking of selfcontrol, who are interested in those amusing and pragmatically contents, the traditional teaching models are losing their attractions and even become more tasteless. Although these students could understand well some theories or analysis courses, some of them may be disgusted at "spoon-fed" teaching methods. Hence, students want to put out the box and like to learn from their own initiative. In fact, the Internet has provided more opportunities for students to access information, which force business schools to provide more interesting, and more practical and instructive courses.

Gap4: the gap between managers' skills demand and student's skills or capabilities (including "soft" skills such as vision, integrity, deep smart, and leadership). With growing competition, more employers prefer to employ personnel with higher "soft" skills rather than personnel with higher "hard" skills. Especially in China, even some international companies intend to recruit employees with higher communication and leadership skills, because Chinese businessmen focus on private influence peddling when they are doing business.

\section{Education using simulation}


Simulation technology is certainly widely used to assist teaching in education field because of capturing the more essential features of real world environment than alternative learning methods. There are a number of literatures dealing with the topic of simulation teaching and student learning in many business fields such as strategic management, marketing, operation management, accounting, and information system (e.g. [2][10]). These advantages of simulation courses are threefold. (1) For business educators, the simulation games indeed had gained another advantage over traditional teaching methods [2]. (2) For students as players, the games may enhance their hand-on capabilities and acquire some critical skills and real-life experiences. (3) For managers of company management, they may present a different and valuable approach to personnel/management training (e.g. HR managers could use the similar simulation programs to discovery, select and train competent people) [14].

\section{Research methodology}

\subsection{Introduction to BizSim Game and The National Business Competi- tion}

Based on the advantages of simulation games, here we use a named BizSim game and a national online business competition as an experiment to investigate why the participants are willing to play this game in their spare time, what they learn from their doing, especially for the players, what skills they can acquire when they are in the simulation processes. These interviews in this research help grounded an innovative "learning by playing" approach for business education. To provide an enterprise management practice platform, the research team and volunteers from Peking University, took more than 20 years to develop the "Simulated business performance management and decisionmaking competition platform". This platform creates a virtual business environment for students to exercise decision-making, which can foster the abilities of decision-making, organizational management and teamwork spirit of students.

BizSim system has integrated many real business scenarios and can be used to launch a large-scale business competition like widely recognized Olympic game. Up till now, we had launched a serial national business competition based on BizSim platform successfully for years. The number of participants was gradually increasing from one thousand players in 2003 to twenty thousand players in 2009 [http://www.bigsai.net/]. Especially in 2009, the national competition game developed into the China Youth Innovation Competition game, and a lot of undergraduates, graduates, MBA and EMBA students and company whitecollars liked to take part in the competition, which attracted over 3,000 teams, more than 20 thousands players from 168 schools and companies. CCTV's produced fspecial programs for the competition, in which outstanding players from the competition demonstrated their management skills and achieved internship or job opportunities in cooperative enterprise of the competition. In addition, more than 40 media included the Xinhua News Agency, Economic Observers, Sina, Sohu, School of Business and Beijing Youth Daily, reported this competition.

The business competition and training must depend on large-scale players to participate together. Thus the national business competition based on BizSim game could really attractive more students from every corner in China. The whole national competition game based on BizSim platform can be viewed as the 
bridge between Job-hunters and students. Many students form different virtual companies to take part in the business simulation game and a social network, though which talented candidates were found out. Then through an interface between candidates and job openings, the candidates can find their future employers, while enterprises can find appropriate people to job openings.

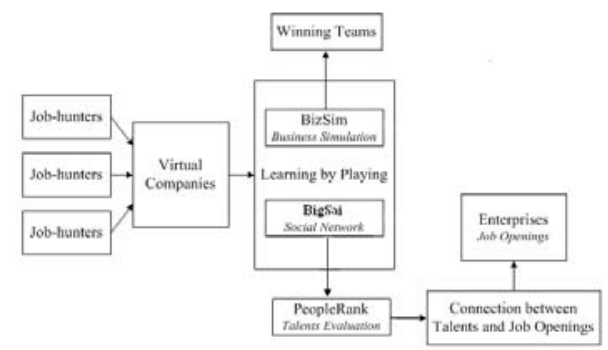

Fig. 2: BizSim simulation platform for competition and recruiting.

The core part of the national competition game includes BizSim platform and BigSai social network. BizSim platform is characterized by closely integrated with the computer application. BigSai is a social network system (SNS) which incorporated an evaluation subsystem called PeopleRank (similar to PageRank algorithm form Google) that everyone can evaluate his/her friends by specific performance evaluation indicator. The whole webbased platform and competitions provide an experiment base for studying the learning by playing model.

\subsection{Grounded theory}

The grounded theory approach proposed by Glaser and Strauss [5] is a practical method for conducting the phenomenon through interpretation and analysis of formation of concepts in real settings [15] It is used to help better understand processes participants use to cope with, respond to, or alter their environment. Because of the complexity of current changing environment of business educations and employment in China, we lacked ideas before we begun with the research phenomenon, and thus we needed the conceptual theory to account for the variation of our studied phenomenon. Figure 3 shows ourresearch process which supports the grounded theory approach for data collection, data analysis, note-taking, memoing, sorting, and writing [4][6].

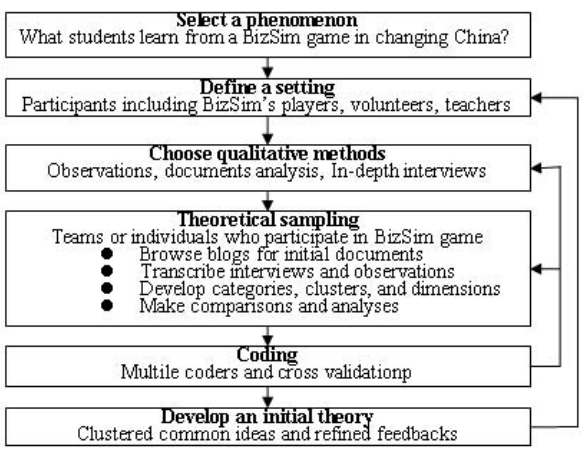

Fig. 3: Grounded theory research process in this study.

Table 1 gives a simple description of these respondents. In this study, a transcript was taken of all comments made using for constant comparison. The goal of an interview taken in this research process was to provide a cross validation for documents derived from blogs of BizSim players through questioning some open-ended questions, i.e., what motivate students like playing BizSim game and what they expected to achieve in this game. We used a serial of open questions to ask players who form a team of five members to play this game and volunteers who organize and manage the game through providing backup support for players and maintaining the daily normal operation of BizSim. And we also ask four teacher proponents some 
questions to question their attitudes on this game.

\begin{tabular}{|c|c|c|}
\hline $\begin{array}{c}\text { Participants } \\
\text { Type }\end{array}$ & Numbers & Institutes \\
\hline $\begin{array}{c}\text { Players/ } \\
\text { Teams }\end{array}$ & $22 / 10$ & $\begin{array}{c}\text { Universities All over } \\
\text { in China }\end{array}$ \\
\hline Volunteers & 6 & Universities in Beijing \\
\hline Teachers & 4 & GSM, PKU \\
\hline
\end{tabular}

Table 1: interviewees of the game in the research process ${ }^{1}$.

\section{Discussions}

This research is an exploratory study based on BizSim participants including players, volunteers, organizers and even organizers using players' comments in their blogs in BigSai Website, a series of focus groups and depth interview. The study found the effectiveness of the learning by playing model has been based upon the fulfillment of overcome the four gaps by a cooperation mechanism.

Figure 5 illustrate the 4 cycles cover for the 4 gaps in business education when business schools introduced a practiceoriented game platform for students.

Cycle 1: Using this platform can help students put theories from classrooms into their "real" business running practice. The game provides an approximate real business world to guide students to use their learned theories and techniques. $80 \%$ of game players suggested that the game could help them put what they had learned from classes or textbook into their actual playing. The change makes business school must improve curriculum and add new knowledge which enterprises need immediately and "soft" skill into curriculum. In this cycle, knowledge and skill will metastasis and metastasis.

\footnotetext{
${ }^{1}$ GSM is the abbreviation of Guanghua School of Management in Peking University.
}

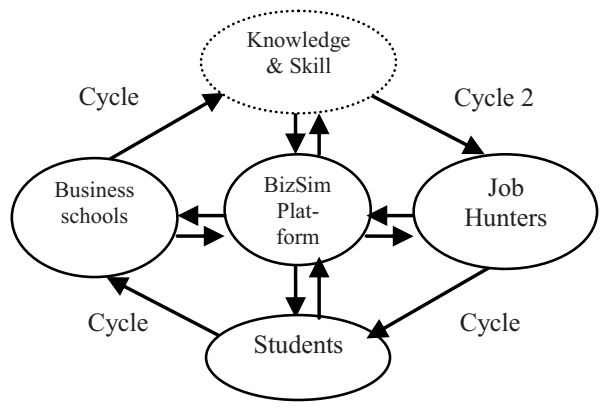

Fig. 5: The gaps of current business education based on BizSim platform.

Cycle 2: The platform provides more opportunities for job hunters to find the suitable people who they want to employ. Under this circumstance, we tried using BizSim game to identify all kinds of talent students (e.g. winners of the game), and then recommended them for competent posts required by job hunters. On the other hand, job hunters feed back the real needs and new changes from the market and enterprises, which will improve business school to change their concept. Meanwhile, talent students who are engaged by managers can use their knowledge and skill to help enterprises to improve on their business model. An economics professor (also a leader of the business school) recognized that the leadership development in this game has great potentialities. He hoped with a strong conviction:"The competitive game can really help to cultivate the best business management team in China. If there will exist world-class enterprises and business leaders in China for every player not just for those winners, they may partly track back to this game when they talk about their reasons of business success. At time, it naturally provides a good proof that the projects have an important effect and a great contribution on the management of China, enterprises of China, and the economy of China".

Cycle 3: The learning by playing method may encourage students to aspire 
after business knowledge and insight. This is also very important cycle. In traditional class, most of students have tired of absorbing knowledge partly because they thought what their school had taught had been separated from the business practice. The "spoon-fed" teaching methods should be changed. Students also "liked the chance to get to know and work with other students in playing" and "learn by playing" model aroused their enthusiasm to gain knowledge. The competition of this game forced them to develop their creativity in order that they could do better than their counterpart. $50 \%$ of players thought that the game provided more motivations to drive them create new ideas and funny tactics different other teams, and $45 \%$ of players believed that the practical running help gain more business experiences and improve their business capabilities and skills with good and systematical understanding about business operations. Some players $(30 \%)$ appreciated the opportunities to intern and train in famous international and state-owned enterprises and the advantages of distinguishing themselves easily to be identified by job hunters. Vast majority of the students showed great interesting and exciting in playing the game whatever their roles were player or volunteers. A new "learning by playing" teaching method can improve business school teaching model.

Cycle 4: The platform makes job hunters change their "hunting" model. Under a kind of approximate real business circumstance, job hunters could know the students well, especially under great press. Just like some students said, "we would follow our way without hesitation, just as a proverb said, "As tiger's den, nothing gained". Actually, "if you provide a suitable stage they would give a perfect performance, and let them do themselves their accomplishment could go beyond what you expected" one volunteer said.

In addition, the new teaching and learning method have some advantages. One is to make use of information technology to provide comprehensive perspectives of business operations. That is, business schools strive to provide students with a rewarding and effective educational experience. A computersimulated enterprise management environment as a complement teaching tool can go with the stream of business education. The very important is "learning by playing" excitated students' enthusiasm and curiosity to gain knowledge and business skill. They can play the simulation game to learn knowledge and win the game to get better job. This cooperation mechanism makes students to accumulate capabilities in a more efficient way, help business schoolprovide better services and attract more students, support enterprises to employ suitable employees.

\section{Conclusions}

The research focuses on current business education problems and uses grounded theory method to explore participant motivations, learning outcomes and acquired skills in the business simulation games

First, we proposed four gaps among the needs of business schools, their students and social employers. These existed gaps partly result into business education failure or crises. Second, we introduce a BizSim platform and a new teaching model "learning by playing" to improve current business education plight. Based on "learning by playing" experiment, we found the mechanism for game based learning and conclude that students prefer to learn what they expected for tomorrow career in this innovative approach. Finally, this paper pointed out that the 
new teaching model becomes a helpful complement for normal teaching. Instead of observed gaps in business education, four cycles make students, business schools and job hunters cooperate with each others and share knowledge. With the "learning by playing" model become more and more popular in the Internet age, more and more business schools will adopt this model to strengthen the training of students' qualities and capabilities including organizing capability, collaboration, decisionmaking, competitive awareness.

\section{References}

[1] Anderson, J. R. (2005). "The relationship between student perceptions of team dynamics and simulation game outcomes: an individual-level analysis", Journal of Education for Business, (81), pp.85-90.

[2] Doyle, D. and F.W. Brown. (2000). "Using a business simulation to teach applied skills - the benefits and the challenges of using student teams from multiple countries", Journal of European Industrial Training, (24)6, pp.330-336.

[3] Galea, C. (2001). "Experiential Simulations: Using Web-Enhanced Role-Plays to Teach Applied Business management", Information Technology and Management, (2) 4, pp.473-489.

[4] Giunipero, L., R.B.Handfield and R. Eltantawy. (2006). "Supply management's evolution: key skill sets for the supply manager of the future", International Journal of Operation \& Production Management, (26)7, pp.822-844.

[5] Glaser, B. G. and A. L.Strauss. (1967). The discovery of grounded theory: Strategies for qualitative research, New York: Aldine.

[6] Glaser, B.G. (1998). Doing Grounded Theory: Issues and Discussions, Sociology Press, Mill Valley, CA.

[7] Guiren Yuan, Chinese Minister of Education. (2009), http://www.chsi.com.cn/jyzx/200911/200 91123/42961 440.htm

[8] Gupta, P.B., J. Smith and P.M. Saunders. (2007). "Traditional Master of Business
Administration (MBA) Versus the MBA with Specialization: A Disconnection between What Business Schools Offer and What Employers Seek", Journal of Education for Business, (82)6, pp.307-312.

[9] Hornaday, R. W., \& Curran, K. E. (1996). "Formal planning and the performance of business simulation teams", Simulation \& Gaming, (27), pp.206-222.

[10]Hwarng, J. B.(2001). "A Modern Simulation Course For Business Students", Interfaces, (31)3,pp.66-75.

[11]Kolb D. A.(1976). "Management and the Learning Process", California Management Review, (18), pp. 21-31.

[12]Mintzberg, H. (2004). Managers not MBAs: A hard look at the soft practice of managing and management development, San Francisco: Berrett-Koehler.

[13]Pfeffer, J. and C.T. Fong. (2002). "The End of Business schools? Less Success than meets the eye", Academy of Management Learning and Education, 1(1), pp.78-95.

[14] Strauss, U. (2006). "Using a business simulation to develop key skills - the MERKIS experience", Industrial and Commercial Training, (38)4, pp. 213-216.

[15] Suddaby, R. (2006). "From The Editors: What Grounded Theory Is Not", Academy of Management Journal, (49)4, pp. 633642.

[16] Yang Xu and Yi Yang. (2010). "Student Learning in Business Simulation: An Empirical Investigation", Journal of Education for Business.(85),pp.223-228. 